\title{
Design of a Memristor-based Chattering Free Sliding Mode Controller and Speed Control of the BLDC Motor
}

\author{
Kamil ORMAN
}

\begin{abstract}
In this study, a memristor-based sliding mode controller (Mem-SMC) was designed for speed control of BLDC motor and the performance of the controller was tested in simulation. The sliding mode controller, known for its robustness against disturbances and parameter variations, was designed with a memristor known as a missing circuit element. Simulation results show that the proposed controller is successful in the speed reference tracking and is also able to respond quickly to sudden changes in the reference.
\end{abstract}

Keywords: BLDC motor; memristor; speed control; sliding mode control

\section{INTRODUCTION}

Brushless DC (BLDC) motors have undergone many changes since they were first designed and are used in many areas of the industry, from transportation to communication, from home electronics to space studies. Brushless DC motors have advantages such as small size, high efficiency and high torque compared to other DC motors and they can be controlled more easily. Because of the studies carried out today, the robust control of BLDC motors is realized thanks to the driver circuits that offer high processing capability and the designed control algorithms.

In the circuits, inductor connects flux and current, resistor provides connection between voltage and current, capacitor connects voltage and charge. It can be said that there is a missing relation between charge and flux when taking into account the four fundamental quantities (voltage, current, flux and charge). This new circuit element provides a connection between charge and flux. Chua defined the new element as memristor (memory + resistor) [1], which connects the missing relationship between charge and flux. Memristor is nonlinear, frequency and history dependent fourth fundamental circuit element. Memristor exhibits pinched hysteresis and linear voltage-current relationship when applied sinusoidal voltage with low and high frequencies, respectively. Researchers think that memristor can be useful when used in classical circuit designs thanks to its interesting properties. Memristor and its applications did not attract researchers' interest until its physical realization in 2008 [2]. But now many types of studies can be found in literature about memristor and its application [3-9].

To date, many studies have been carried out for speed control of brushless DC motors. Zhang and Wang proposed a model-based PID controller that adjusts PID parameters to control the speed of the motor using the voltage equation and torque and speed equation of the brushless DC motor [10]. In the study given in [11], an inverse model of BLDC motor speed was created by using artificial neural network (ANN) and the model was used as a controller. Hassan et al. [12] in their simulation study tested PID controller, Fuzzy logic controller and Neuro fuzzy controller to control the speed of a brushless DC motor. Verma et al. have tested the speed control of the BLDC motor drive with different controllers [13]. They compared the performance of the proposed zero-crossing detection of indirect back EMF technique with different controllers such as a PI controller, anti-windup PI, and Hybrid (Fuzzy-PI) controllers at different loads and speeds. They also stated that the Neuro fuzzy controller is a very complex controller but has a very good performance. The effectiveness of the study was demonstrated by simulation and the results were analyzed.

The most significant advantage of the sliding mode control (SMC) method is the ability to eliminate the effects of uncertainties caused by model errors and unwanted disturbances that affect the system response. Therefore, different and hybrid structures of the SMC method, which is known as robust control technique, have been designed by researchers and applied for different systems [14-22]. The disadvantage of this method is the chattering effect, which means oscillation in the control signal.

In this study, a design for the sliding mode control approach was proposed and the controller was designed using memristor known as a missing circuit element. The performance of the memristor based SMC (Mem-SMC) was tested in the speed control of the BLDC motor and the success of the controller was presented with simulation results.

\section{BASIC DEFINITION of BLDC MOTOR and MEMRISTOR 2.1 BLDC Motor Model}

The transfer function of the BLDC motor can be expressed by considering the equations of voltage and mechanical part of the DC motor given below.

$$
\begin{aligned}
& V=L \frac{\mathrm{d} i}{\mathrm{~d} t}+i R+K_{\mathrm{e}} \frac{\mathrm{d} \varphi}{\mathrm{d} t} \\
& i=\frac{1}{K_{\mathrm{t}}}\left(J_{\mathrm{m}} \frac{\mathrm{d}^{2} \varphi}{\mathrm{d} t^{2}}+B_{\mathrm{m}} \frac{\mathrm{d} \varphi}{\mathrm{d} t}\right)
\end{aligned}
$$

where $L$ is phase inductance, $\mathrm{mH} ; R$ is resistance between phases, $\Omega ; J_{\mathrm{m}}$ motor inertia, $\mathrm{kgm}^{2} ; B_{\mathrm{m}}$ is friction coefficient, $\mathrm{Nm} /(\mathrm{rad} / \mathrm{s}) ; K_{\mathrm{e}}$ is back-emf constant, $\mathrm{Vs} / \mathrm{rad}$; $K_{\mathrm{t}}$ is torque constant, $\mathrm{mNm} / \mathrm{A}$. First, (1) and (2) can be 
written in $s$-form to achieve the transfer function of the system.

$$
\begin{aligned}
& V(s)=L s I(s)+R I(s)+K_{e} s \varphi(s) \\
& I(s)=\frac{1}{K_{\mathrm{t}}}\left(J_{\mathrm{m}} s^{2} \varphi(s)+B_{\mathrm{m}} s \varphi(s)\right)
\end{aligned}
$$

If (3) is rearranged and replaced in (4)

$$
\begin{aligned}
& I(s)=\frac{V(s)-K_{\mathrm{e}} s \varphi(s)}{R+L s} \\
& \frac{K_{\mathrm{t}}\left[V(s)-K_{\mathrm{e}} s \varphi(s)\right]}{R+L s}=J_{\mathrm{m}} s^{2} \varphi(s)+B_{\mathrm{m}} s \varphi(s)
\end{aligned}
$$

is obtained. If (6) is rearranged to obtain $V(s)$

$$
V(s)=\frac{\varphi(s)\left[J_{\mathrm{m}} s^{2}+B_{\mathrm{m}} s\right][R+L s]+K_{\mathrm{t}} K_{\mathrm{e}} s \varphi(s)}{K_{\mathrm{t}}}
$$

and if (7) is rewritten to make the $\omega(s)=s \varphi(s)$ conversion here;

$\frac{s \varphi(s)}{V(s)}=\frac{K_{\mathrm{t}}}{\left[J_{\mathrm{m}} s+B_{\mathrm{m}}\right][R+L s]+K_{\mathrm{t}} K_{\mathrm{e}}}$

$$
\frac{\omega(s)}{V(s)}=\frac{K_{\mathrm{t}}}{\left[J_{\mathrm{m}} s+B_{\mathrm{m}}\right][R+L s]+K_{\mathrm{t}} K_{\mathrm{e}}}
$$

So that after the (9) is obtained, the transfer function of the system can be written as follows.

$$
G(s)=\frac{\omega(s)}{V(s)}=\frac{K_{\mathrm{t}}}{\left[J_{\mathrm{m}} s+B_{\mathrm{m}}\right][R+L s]+K_{\mathrm{t}} K_{\mathrm{e}}}
$$

Eq. (10) can be simplified by making the following assumptions.

- $B_{\mathrm{m}}$ tends to go too small and even zero,

- $J_{\mathrm{m}} R \gg B_{\mathrm{m}} L$

- $K_{\mathrm{t}} K_{\mathrm{e}}>>B_{\mathrm{m}} R$

and if very small values are neglected, the transfer function can be written as below.

$G(s)=\frac{K_{t}}{L J_{\mathrm{m}} s^{2}+J_{\mathrm{m}} R s+K_{\mathrm{t}} K_{\mathrm{e}}}$

If (11) is multiplied by

$$
\frac{\left(\frac{R}{K_{\mathrm{t}} K_{\mathrm{e}}} \cdot \frac{1}{R}\right)}{\left(\frac{R}{K_{\mathrm{t}} K_{\mathrm{e}}} \cdot \frac{1}{R}\right)}
$$

and the transfer function is rewritten;

$$
G(s)=\frac{\frac{1}{K_{\mathrm{e}}}}{\frac{R J_{\mathrm{m}}}{K_{\mathrm{t}} K_{\mathrm{e}}} \frac{L}{R} s^{2}+\frac{R J_{\mathrm{m}}}{K_{\mathrm{t}} K_{\mathrm{e}}} s+1}
$$

is obtained. Electrical time constant and Mechanical time constant are:

$\tau_{\mathrm{e}}=\frac{L}{R}, \quad \tau_{\mathrm{m}}=\frac{R J_{\mathrm{m}}}{K_{\mathrm{t}} K_{\mathrm{e}}}$

If the electrical and mechanical time constants given in (13) are used in (12), the transfer function of the system is obtained;

$G(s)=\frac{\frac{1}{K_{\mathrm{e}}}}{\tau_{\mathrm{e}} \tau_{\mathrm{m}} s^{2}+\tau_{\mathrm{m}} s+1}$

The mechanical and electrical time constants given in (13) are very important in the motor model and show the difference between the DC motor and the BLDC motor.

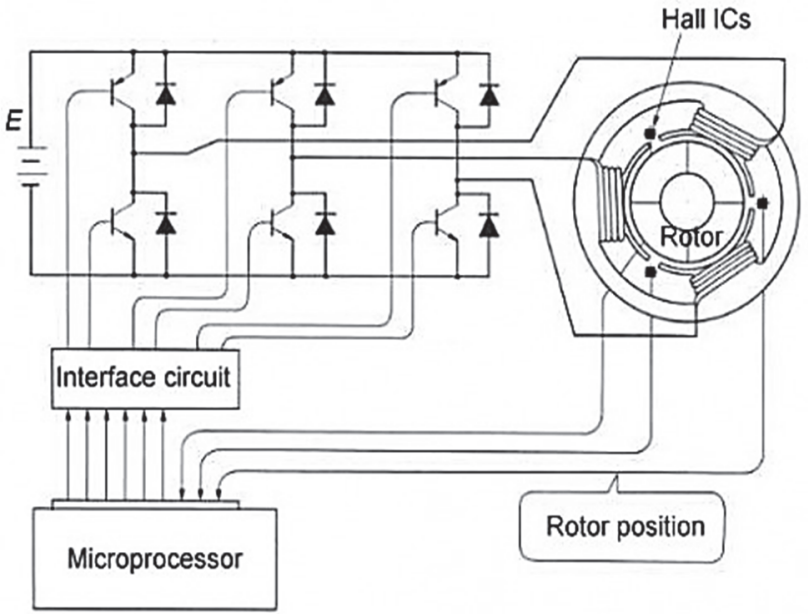

Figure 1 Typical BLDC Motor and driver [23]

Due to the 3-phase symmetrical structure of the BLDC motor shown in Fig.1, (13) can be rewritten as follows.

$\tau_{\mathrm{e}}=\sum \frac{L}{R}=\frac{L}{3 R}, \quad \tau_{\mathrm{m}}=\sum \frac{R J_{\mathrm{m}}}{K_{\mathrm{t}} K_{\mathrm{e}}}=\frac{J_{\mathrm{m}} 3 R}{K_{\mathrm{t}} K_{\mathrm{e}}}$

On the other hand, to determine the relationship between mechanical and electrical torques, electrical energy and mechanical power equations can be expressed as follows:

$$
\begin{aligned}
& \sqrt{3} E I=\frac{2 \pi}{60} N T, \quad \frac{E}{N}=\frac{2 \pi T}{60 \sqrt{3} I} \\
& K_{\mathrm{e}}=\frac{2 \pi}{60 \sqrt{3}} K_{\mathrm{t}}=0.0605 K_{\mathrm{t}}
\end{aligned}
$$


where $T$ is tork, $N$ is rotating speed and $E, I$ are motor voltage and currents, respectively.

In order to obtain the transfer function of the BLDC motor to be used in the simulation study, the parameters of the BLDC motor of Maxonmotor (EC-32) to be used in (14) are given in Tab. 1 and Tab. 2.

Table 1 The operation features of Maxon BLDC motor [24]

\begin{tabular}{|c|c|c|}
\hline S. No. & Parameter (unit) & Specification \\
\hline 1 & Nominal voltage - V & 24 \\
\hline 2 & No load speed - rpm & 11000 \\
\hline 3 & No load current - mA & 286 \\
\hline 4 & Nominal speed - rpm & 9510 \\
\hline 5 & Nominal torque - mNm & 43.6 \\
\hline 6 & Nominal current - A & 3.37 \\
\hline 7 & Stall torque - mNm & 355 \\
\hline 8 & Starting current - A & 17.3 \\
\hline 9 & Maximum efficiency & $76 \%$ \\
\hline
\end{tabular}

Table 2 Maxon BLDC motor's characteristic features [24]

\begin{tabular}{|c|c|c|}
\hline S. No. & Parameter (unit) & Specification \\
\hline 1 & $\begin{array}{c}\text { Terminal resistance } \\
\text { phase to phase }-\Omega\end{array}$ & 1.39 \\
\hline 2 & $\begin{array}{c}\text { Terminal inductance } \\
\text { phase to phase - mH }\end{array}$ & 0.226 \\
\hline 3 & $\begin{array}{c}\text { Torque constant - } \\
\text { mNm/A }\end{array}$ & 465 \\
\hline 4 & Speed constant - rpm/V & 31.5 \\
\hline 5 & $\begin{array}{c}\text { Speed/torque gradient - } \\
\text { rpm/mNm }\end{array}$ & 6.59 \\
\hline 6 & $\begin{array}{c}\text { Mechanical time } \\
\text { constant - ms }\end{array}$ & 20 \\
\hline 7 & Rotor inertia- gcm ${ }^{2}$ & \\
\hline
\end{tabular}

$\tau_{\mathrm{e}}$ and $K_{\mathrm{e}}$ vales require calculation so if the following calculations are made according to the values given in the tables above.

$\tau_{\mathrm{e}}=\frac{L}{3 R}=\frac{0.226 \times 10^{-3}}{3 \cdot 1.39}=54.19 \times 10^{-6} \mathrm{~s}$

$K_{\mathrm{e}}=\frac{3 R J_{\mathrm{m}}}{\tau_{\mathrm{m}} K_{\mathrm{t}}}=\frac{3 \cdot 1.39 \cdot 2.26 \times 10^{-6}}{6.59 \times 10^{-3} \cdot 20.5 \cdot 10^{-3}}=0.06173 \mathrm{Vs} / \mathrm{rad}$

These values are substituted in Eq. (14) and the transfer function of BLDC motor is obtained as follows.

$$
\begin{aligned}
& G(s)=\frac{\frac{1}{0.06173}}{54.19 \times 10^{-6} \cdot 6.59 \times 10^{-3} \cdot s^{2}+6.59 \times 10^{-3} \cdot s+1} \\
& G(s)=\frac{16.19}{0.357 \times 10^{-6} \cdot s^{2}+6.59 \times 10^{-3} \cdot s+1}
\end{aligned}
$$

\subsection{Memristor}

A memristor (memory resistor) is a non-linear twoterminal electrical component relating electric charge and magnetic flux linkage. It was described and named in 1971 by Leon Chua, completing a theoretical quartet of fundamental electrical components which comprises also the resistor, capacitor and inductor [1]. Later on, it was produced in 2008 by HP researchers [2]. The relationship between current and voltage of the memristor can generally be expressed as follows.

$$
V(t)=R(t) i(t)=\frac{\mathrm{d} \varphi}{\mathrm{d} Q} i(t)
$$

where, $\varphi$ and $Q$ denote the flux and charge, respectively and the memristor resistance, termed memristance, is expressed as the ratio of flux to charge. The relationship between voltage and current proposed by HP research group for $\mathrm{TiO}_{2}$ memristor.

$$
V(t)=\left[R_{\mathrm{ON}} \frac{x(t)}{D}+R_{\mathrm{OFF}}\left(1-\frac{x(t)}{D}\right)\right] i(t)
$$

where, $R_{\mathrm{OFF}}$ and $R_{\mathrm{ON}}$ are high and low resistance states, respectively, $D$ and $x$ denote the thickness of $\mathrm{TiO}_{2}$ memristor and the doped area, respectively. The resistance value directly depends on the change of the $x$ value and is defined as

$$
\frac{\mathrm{d} x(t)}{\mathrm{d} t}=\mu_{v} \frac{R_{\mathrm{ON}}}{D} i(t)
$$

where, $\mu_{v}$ is the mobility of memristor and also the memristors exhibit a stuck hysteresis voltage-current relationship when sinusoidal signal is applied, and nonlinearity decreases with increasing frequency such as in Fig. 2.

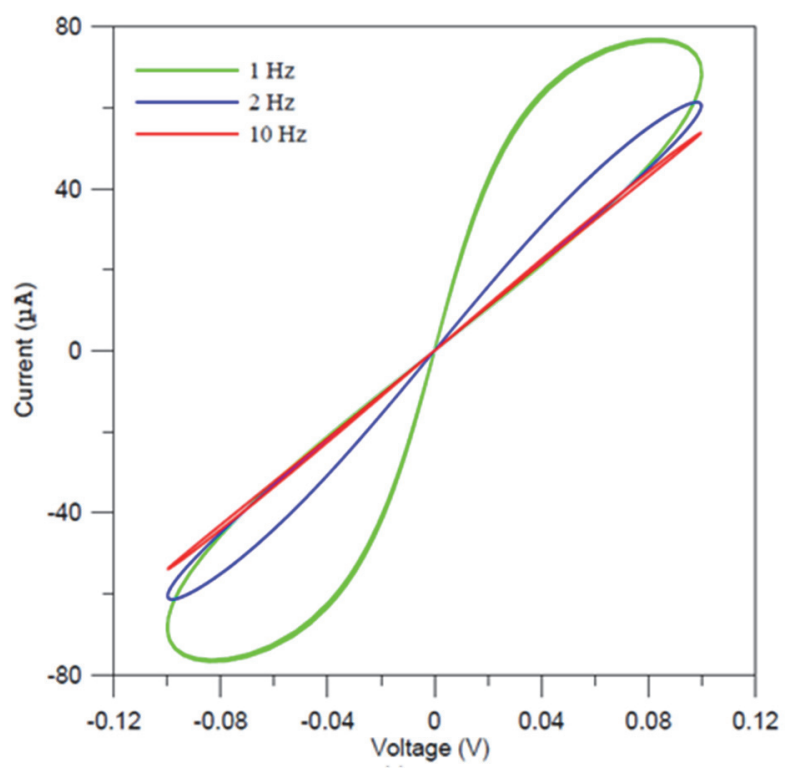

Figure 2 Memristor voltage-current relationship with various frequencies [25]

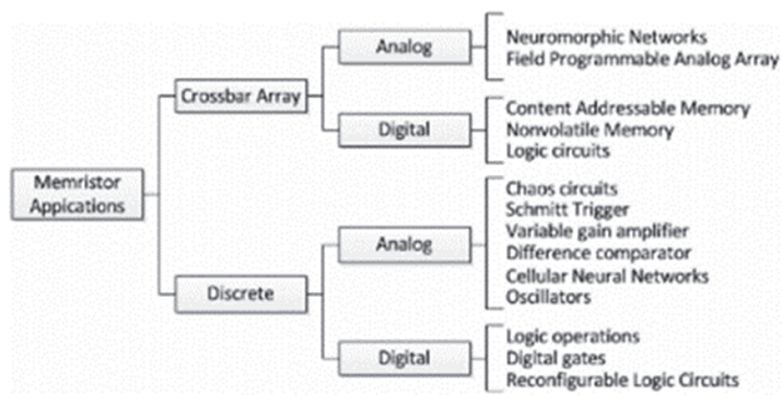

Figure 3 The application areas of memrsitor [26] 
Memristor as nonlinear circuit elements have many types of applications from analog to digital circuits. Mazumder categorized the applications of memristor as in Fig. 3 [26].

\section{CONTROL}

\subsection{Sliding Mode Controller}

The error of the variable to be controlled and the sliding surface of the SMC to be designed can be defined as follows.

$$
\begin{aligned}
& e(t)=x_{\text {ref }}(t)-x(t) \\
& s=\{x: \varepsilon(x, t)=0\}
\end{aligned}
$$

The second order system controlled by the SMC can be defined as follows;

$$
m \ddot{x}(t)+b \dot{x}(t)+k x(t)=u(t)
$$

If $\dot{x}=\sigma$ transformation is used to convert this second order system to first order system;

$$
\begin{aligned}
& \ddot{x}=\dot{\sigma}=\frac{1}{m}(u-b \sigma-k x) \\
& {\left[\begin{array}{c}
\dot{x} \\
\dot{\sigma}
\end{array}\right]=\left[\begin{array}{cc}
0 & 1 \\
\frac{-k}{m} & \frac{-b}{m}
\end{array}\right]\left[\begin{array}{l}
x \\
\sigma
\end{array}\right]+\left[\begin{array}{c}
0 \\
\frac{1}{m}
\end{array}\right] u} \\
& {[\dot{x}]=f(x, t)+B u}
\end{aligned}
$$

The sliding function $\varepsilon$ in (26) can be determined as follows;

$$
\varepsilon=D e=D\left(x_{\text {ref }}-x\right)=\phi(t)-\varphi(x)
$$

$$
\begin{aligned}
& \phi(t)=D x_{\mathrm{ref}} \\
& \varphi(x)=D x \\
& \frac{\mathrm{d} \varphi(x)}{\mathrm{d} x}=D
\end{aligned}
$$

where $D$ is the design parameter. If the derivative of the sliding function is equated to zero, the solution to be obtained is called the equivalent controller. The derivative of the sliding function;

$$
\frac{\mathrm{d} \varepsilon}{\mathrm{d} t}=\frac{\mathrm{d} \phi(t)}{\mathrm{d} t}-\frac{\mathrm{d} \varphi(x)}{\mathrm{d} x} \frac{\mathrm{d} x}{\mathrm{~d} t}
$$

If this equation is rewritten using (30) and (32);

$$
\frac{\mathrm{d} \varepsilon}{\mathrm{d} t}=\frac{\mathrm{d} \phi(t)}{\mathrm{d} t}-D(f(x, t)+B u)
$$

If (34) is equal to zero, the control signal to be obtained is equivalent control $\left(u=u_{\text {eq }}\right)$.

$$
\left.\frac{\mathrm{d} \varepsilon}{\mathrm{d} t}\right|_{u=u_{\mathrm{eq}}}=\frac{\mathrm{d} \phi(t)}{\mathrm{d} t}-D\left(f(x, t)+B u_{\mathrm{eq}}\right)=0
$$

$$
D B u_{\mathrm{eq}}=\frac{\mathrm{d} \phi(t)}{\mathrm{d} t}-D(f(x, t)
$$

In order for the closed loop system to be stable, an appropriate Lyapunov function can be selected as [27, 28].

$V=\frac{1}{2} \varepsilon^{T} \varepsilon>0$ and $\dot{V}=\varepsilon^{T} \dot{\varepsilon}$

For stability:

$$
\dot{V}=-\varepsilon^{T} G \varepsilon<0
$$

here $G$ determines the speed of approach of the system states to the sliding surface and if the derivatives in (37) and (38) are equalized,

$\varepsilon^{T} \dot{\varepsilon}=-\varepsilon^{T} G \varepsilon$

$\varepsilon^{T}(\dot{\varepsilon}+G \varepsilon)=0$

$\dot{\varepsilon}+G \varepsilon=0$

is obtained. If (34) is replaced by Eq. (41) to obtain the control signal,

$\frac{\mathrm{d} \phi(t)}{\mathrm{d} t}-D(f(x, t)+B u)+D \varepsilon=0$

$\frac{\mathrm{d} \phi(t)}{\mathrm{d} t}-D f(x, t)+D B u+D \varepsilon=0$

In addition, considering (36).

$D B u_{\mathrm{eq}}-D B u+G \varepsilon=0$

By performing a simple mathematical operation, the control sign is obtained as follows.

$u=u_{\mathrm{eq}}+K \varepsilon$

where $K=G / D B$. This will eliminate the chattering effect with the help of a continuous signal, $(K \varepsilon)$, added to the equivalent control signal $\left(u_{\text {eq }}\right)$. If $f(x, t)$ and $B$ are unknown or very little known, $\left(u_{\text {eq }}\right)$ 'cannot be calculated or will be very different from the actual $\left(u_{\text {eq }}\right)$. If the physical effect of the equivalent control is considered, the average value of the total control can be regarded as equivalent control. In this case, it would be appropriate to design a low-pass filter that determines the average of the entire signal instead of 
the rapidly changing high-frequency components in the total control signal to find equivalent control.

$u=u_{\mathrm{eq}}+\Delta u+K \varepsilon$

where $\Delta u$ is the high-frequency components within the total control signal and $u_{\text {eq }}$ is the average value of the total control signal. In this case, a low pass filter may be designed for the estimated equivalent control signal $\left(\hat{u}_{\text {eq }}\right)$ as follows.

$\hat{u}=\hat{u}_{\mathrm{eq}}+\tau \hat{u}_{\mathrm{eq}}$

$\hat{u}_{\mathrm{eq}}=\frac{1}{1+\tau S} u$

Here $\tau=1 / f_{\mathrm{c}}$ is the cut-off frequency of low-pass filter. If $\hat{u}_{e q}$ is written in (45) instead of $u_{\text {eq }}$.

$u=\hat{u}_{\mathrm{eq}}+K \varepsilon$

$u=\frac{1}{1+\tau S} u+K \varepsilon$

For a robust control approach, it is necessary to control the error and the speed of the error. Therefore, $\varepsilon$ can be determined as follows.

$\varepsilon=\dot{e}+D e$

As a result, if (51) is substituted in (50), the control signal is obtained as follows.

$u=\frac{1}{1+\tau s} u+K(\dot{e}+D e)$

\subsection{Memristor-based Differentiator}

In the differentiator circuit shown in Fig. 4, the resistance of the Memistor is automatically changed by its voltage, which can be used as an adjustable gain [29].

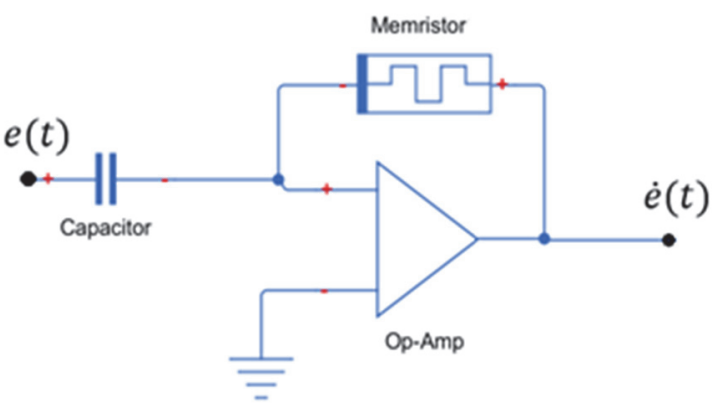

Figure 4 Memristor-based Differentiator Circuit

The Eq. (53) represents the mathematical expression of memristor based derivator circuit and it is given as.

$\dot{e}(t)=M C \frac{\mathrm{d} e(t)}{\mathrm{d} t}$ where, $M$ represents the memristance and $C$ is capacitance.

\subsection{Memristor-based Low-Pass Filter}

The low-pass filter shown in Fig. 5 has an adjustable gain and adjustable cut-off frequency as the memristor memristance can change as a function of the memristor charge [30].

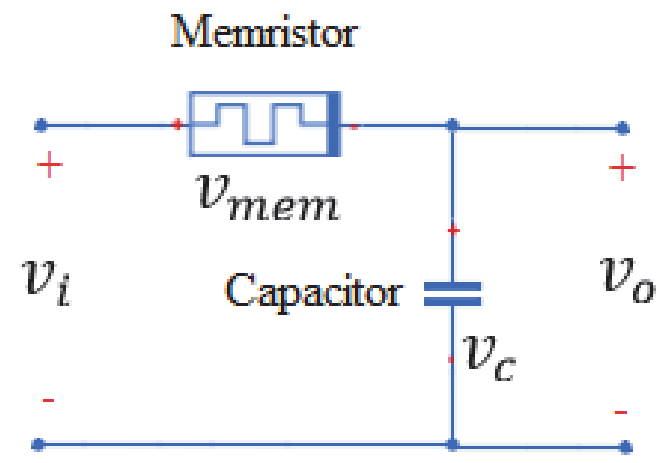

Figure 5 Memristor Based Low-Pass Filter Circuit

The filter cut-off frequency and the filter gain are:

$f_{\mathrm{c}}=\frac{1}{\tau}=\frac{\omega_{\mathrm{c}}}{2 \pi}=\frac{1}{2 \pi \bar{M} C}$

$G_{\mathrm{LPd} B}=20 \log \left(\frac{1}{\sqrt{1+(\omega C \bar{M})^{2}}}\right)$

In the above equations, $M$ is the memristance of the memristor, $C$ is the capacitance and $f_{\mathrm{c}}$ is the cut-off frequency of low-pass filter.

\subsection{Memristor-based Sliding Mode Controller}

If the derivative operation and low-pass filter in the sliding mode control signal given in (52) is carried out by the memristor based derivator and filter circuits, the control signal can be written as follows.

$u=\frac{1}{1+\tau s} u+K\left(\mathrm{MC} \frac{\mathrm{d} e(t)}{\mathrm{d} t}+D e\right)$

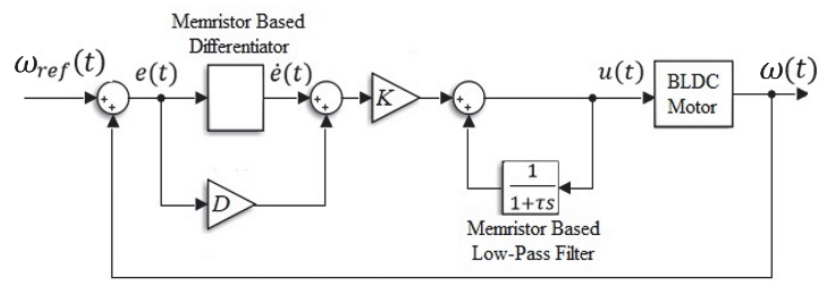

Figure 6 Speed control of the BLDC motor with Memristor based sliding mode control (Mem-SMC)

The block diagram of the speed control of the BLDC motor with the memristor based sliding mode control (Mem-SMC) approach is given in Fig. 6. 


\section{SIMULATION}

First of all, in the simulation study, the memristor model in Matlab (2016a)/Simulink Simscape model library was used. The model parameters are set as shown in Fig. 7. The model parameter state-A and state-B resistances are $R_{\mathrm{ON}}$ and $R_{\mathrm{OFF}}$ resistance values in Eq. (23), respectively.

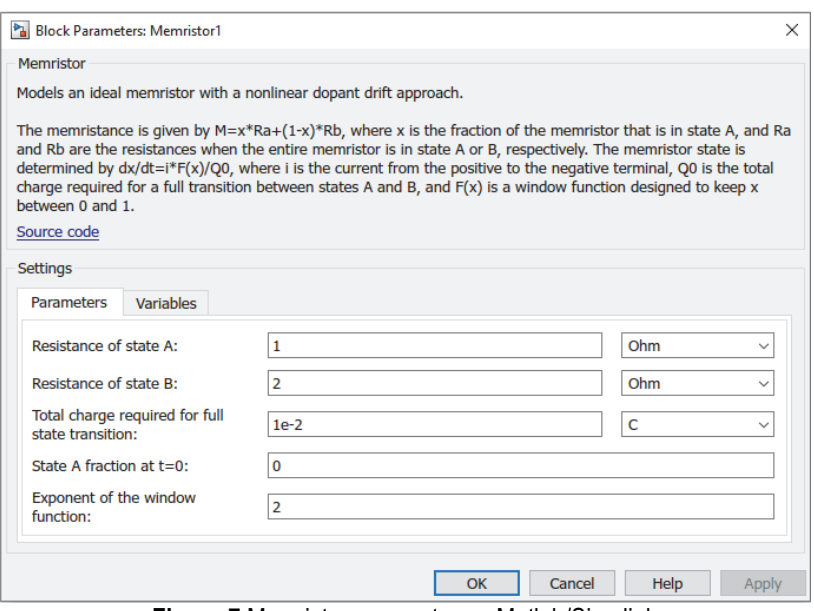

Figure 7 Memristor parameter on Matlab/Simulink

In this section, the proposed controller is tested for reference tracking and error reduction and the results are given in Figs. 8 to 15 . As a reference, a trapezoidal speed reference with soft changes was first selected, followed by a square speed reference with sudden changes. In the first simulation study, $10 \mathrm{rpm}$ trapezoidal and $10 \mathrm{rpm}$ square speed references was applied.
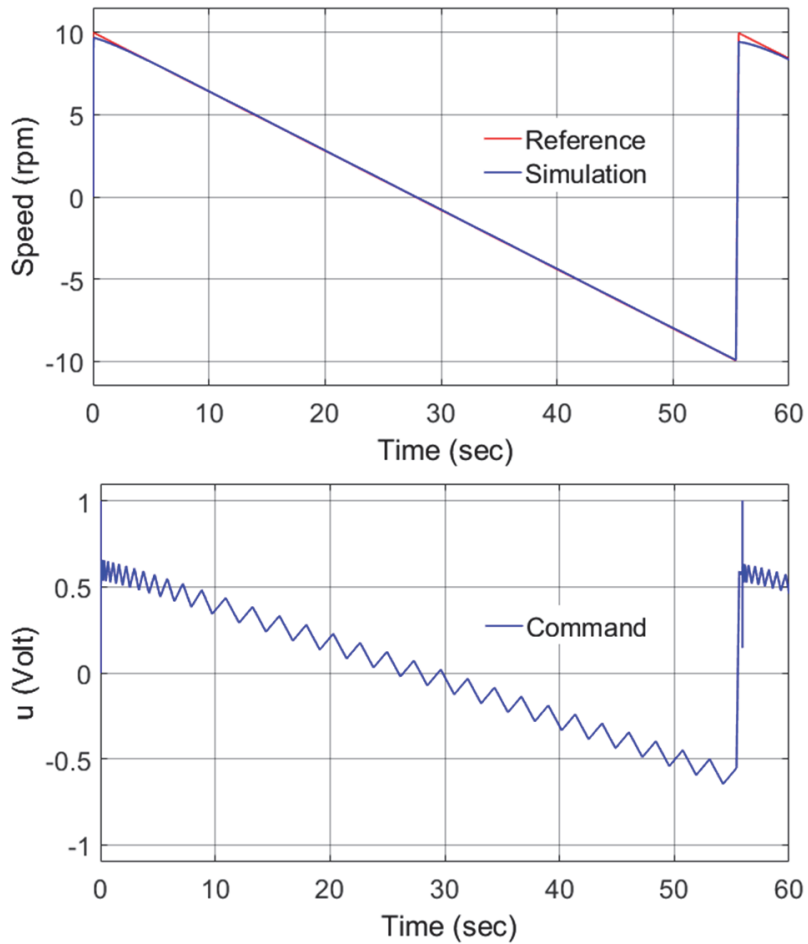

Figure 810 rpm trapezoidal speed ref. $\left(R_{\mathrm{ON}}=1 \Omega\right.$ and $\left.R_{\mathrm{OFF}}=2 \Omega\right)$

As shown in Fig. 8 and Fig. 9, the Mem-SMC has reached the reference at about 5 seconds in both references and has successfully followed the speed reference and the error is around $0.01 \%$. However, when the control signs were examined in Fig.8 and Fig. 9, chattering effect was observed despite the application of Continuous sliding mode control approach.
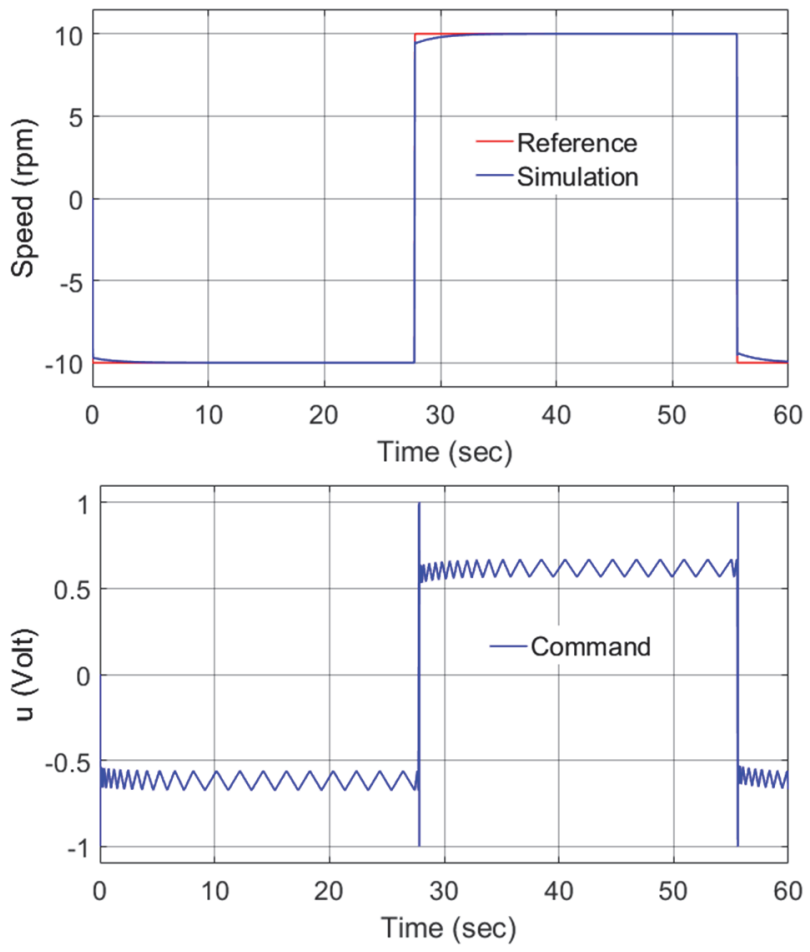

Figure $910 \mathrm{rpm}$ square speed ref. $\left(R_{\mathrm{ON}}=1 \Omega\right.$ and $\left.R_{\mathrm{OFF}}=2 \Omega\right)$

In the second simulation study, $R_{\mathrm{ON}}$ and $R_{\mathrm{OFF}}$ values of Memristor for the same reference signals were adjusted by trial and error method $\left(R_{\mathrm{ON}}=2.3 \Omega\right.$ and $\left.R_{\mathrm{OFF}}=3.1 \Omega\right)$ and the results in Fig. 10 and Fig. 11 were obtained. The Chattering effect in the control signal is eliminated. Moreover Mem-SMC has a faster reaching time when the speed reference changes to the $\pm 10 \mathrm{rpm}$. In addition, the Mem-SMC has no overshoot during sudden changes in the reference.
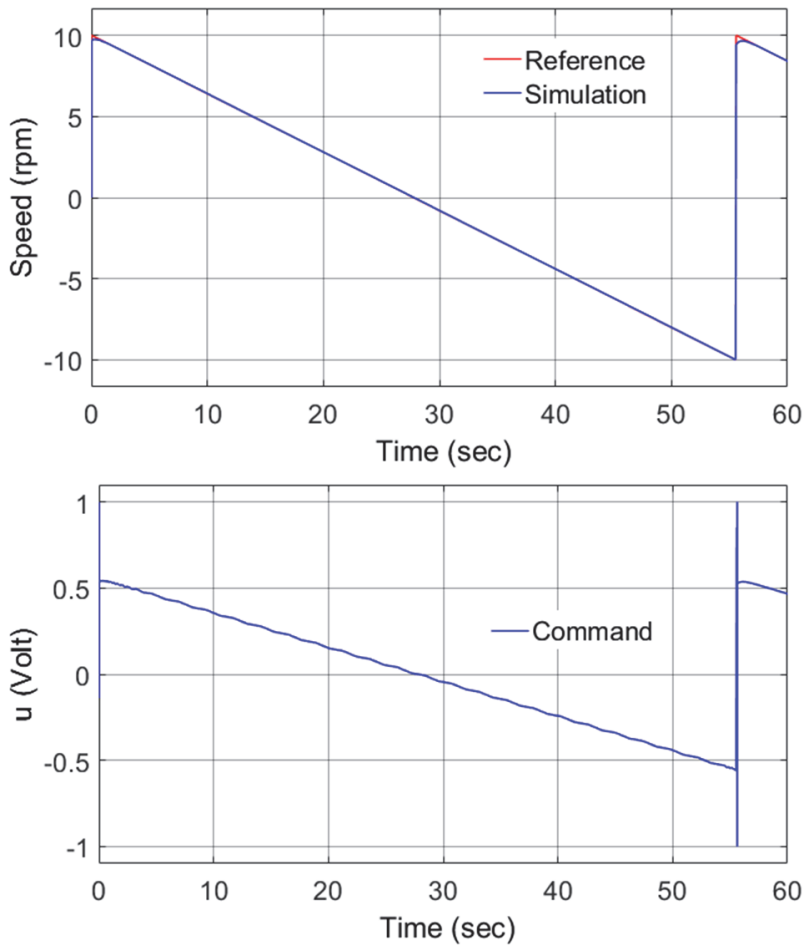

Figure $1010 \mathrm{rpm}$ trapezoidal speed ref. $\left(R_{\mathrm{ON}}=2.3 \Omega\right.$ and $\left.\mathrm{R}_{\mathrm{OFF}}=3.1 \Omega\right)$ 

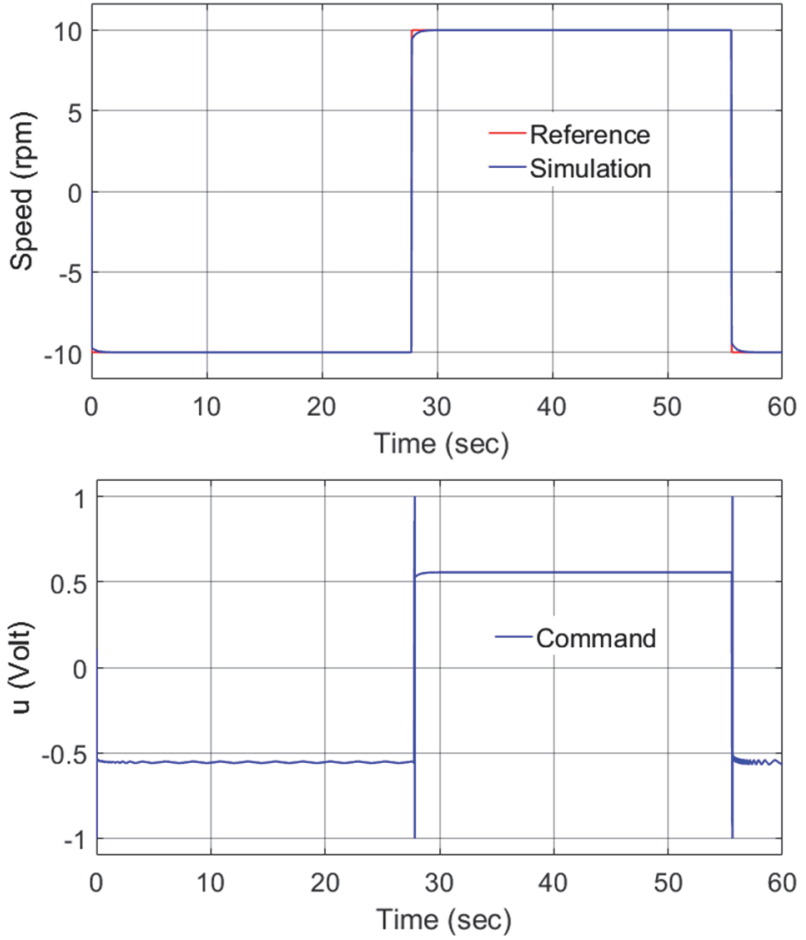

Figure $1110 \mathrm{rpm}$ square speed ref. $\left(R_{\mathrm{ON}}=2.3 \Omega\right.$ and $\left.R_{\mathrm{oFF}}=3.1 \Omega\right)$

Then, $1000 \mathrm{rpm}$ trapezoidal and $1000 \mathrm{rpm}$ square references were applied respectively to test the performance of the controller at high speeds. When $R_{\mathrm{ON}}=$ $1 \Omega$ and $R_{\mathrm{OFF}}=2 \Omega$ are selected in the memristor parameters, the obtained results are given in Fig. 12 and Fig. 13. The reaching time of the Mem-SMC for both references is around 1 second. In addition, the error in reference tracking is around $+/-0.01$, and the chattering effect occurred during the time of reaching the reference in the control signs.
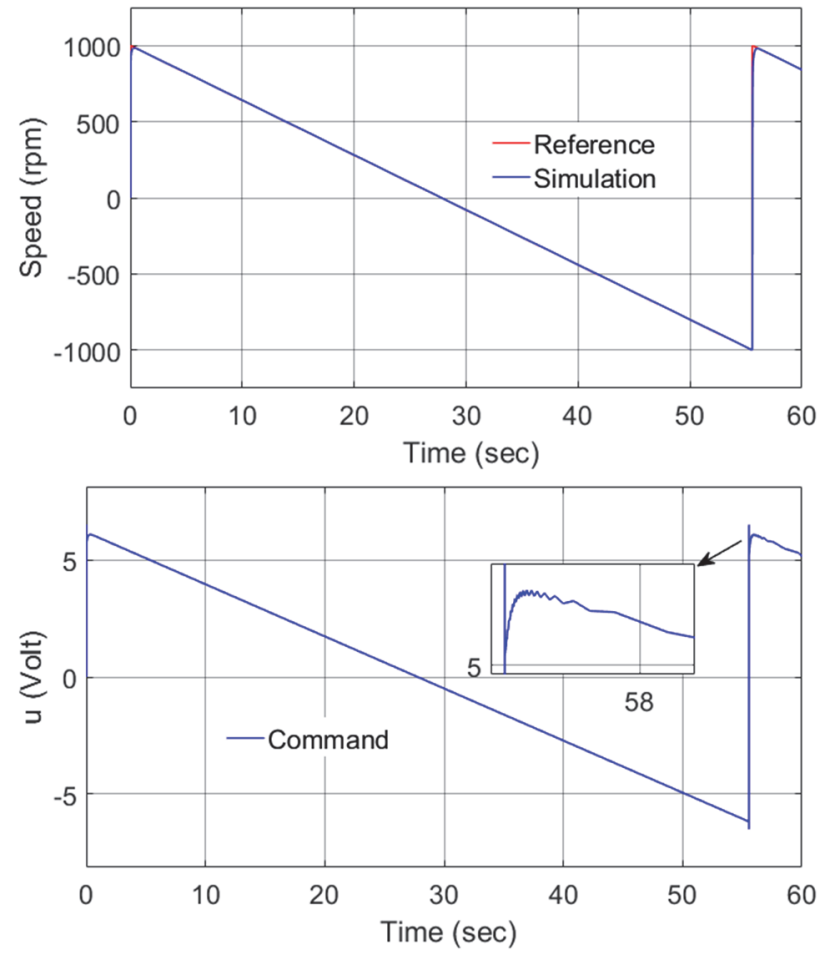

Figure $1210 \mathrm{rpm}$ trapezoidal speed ref. $\left(R_{\mathrm{ON}}=1 \Omega\right.$ and $\left.R_{\mathrm{OFF}}=2 \Omega\right)$
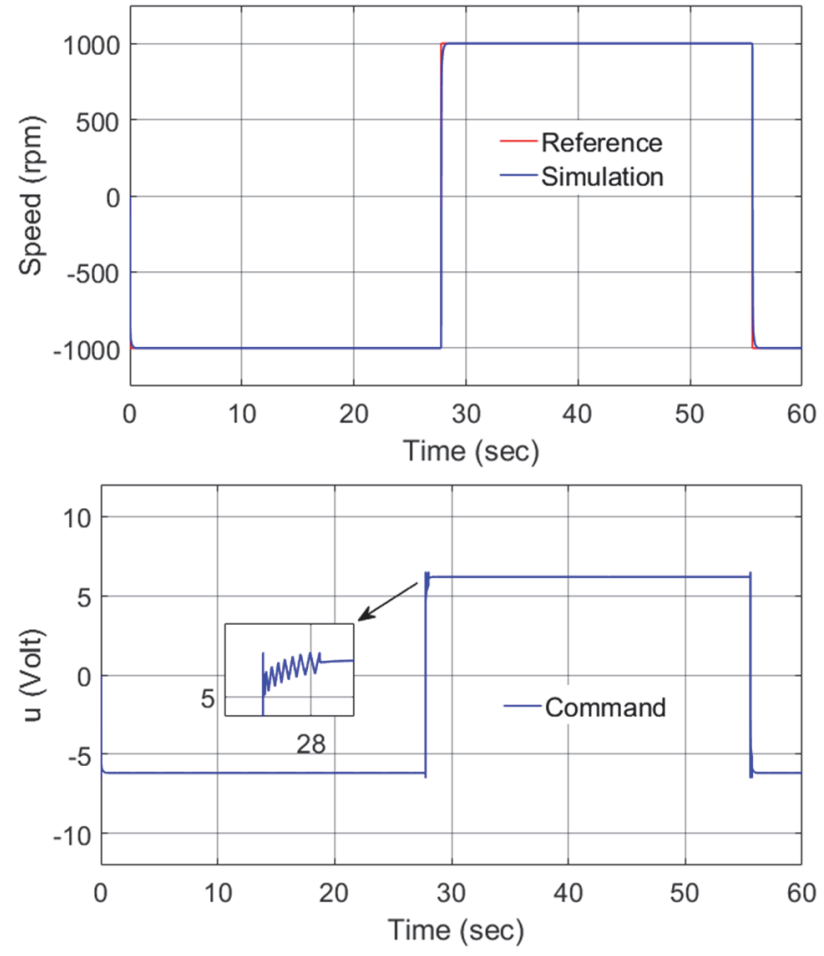

Figure $1310 \mathrm{rpm}$ square speed ref. $\left(R_{\mathrm{ON}}=1 \Omega\right.$ and $\left.R_{\mathrm{OFF}}=2 \Omega\right)$

After the reference was reached, the chattering effect in the control signals disappeared. Finally, when the parameters in the memristor model in Matlab/Simulink are set to $R_{\mathrm{ON}}=2.3 \Omega$ and $R_{\mathrm{OFF}}=3.1 \Omega$, the obtained results are given in Fig. 14 and Fig. 15. The reaching time to both references is around 0.5 seconds, and the chattering effect in the control signals has disappeared and smooth control signals were obtained. In addition, the Mem-SMC has no overshoot.
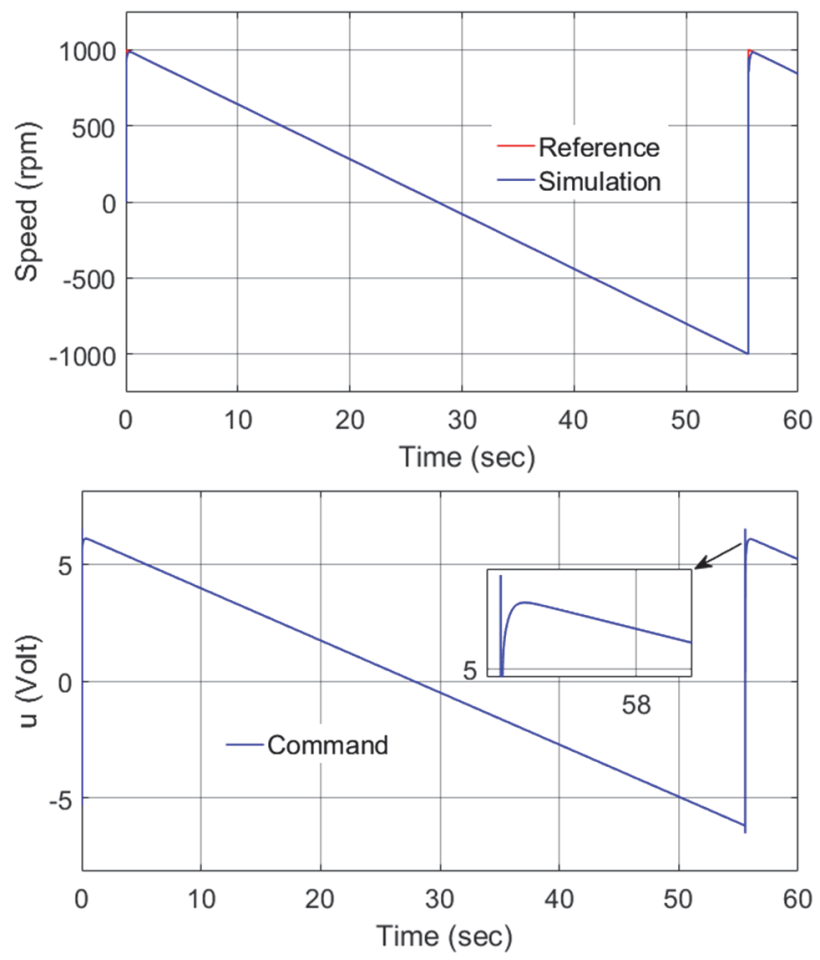

Figure $1410 \mathrm{rpm}$ trapezoidal speed ref. $\left(R_{\mathrm{ON}}=2.3 \Omega\right.$ and $\left.R_{\mathrm{OFF}}=3.1 \Omega\right)$ 

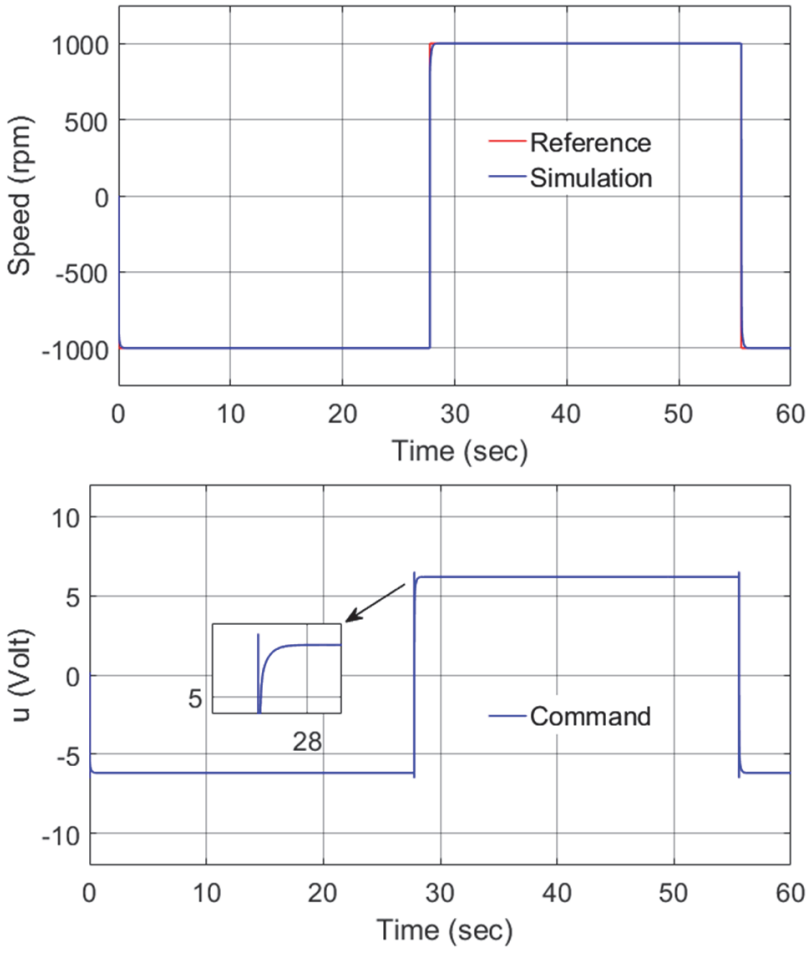

Figure $1510 \mathrm{rpm}$ square speed ref. $\left(R_{\mathrm{oN}}=2.3 \Omega\right.$ and $\left.R_{\mathrm{OFF}}=3.1 \Omega\right)$

\section{CONCLUSIONS}

In this study, a memristor-based sliding mode controller is tested in the speed control of BLDC motor and simulation results are presented. It has been shown that the Memristor can be applied in nonlinear control methods by means of a sliding mode controller designed using a Memristor known as a missing circuit element. Simulation results show that Mem-SMC is successful in speed control of BLDC motor. However, the chattering effect seen in the control signal in the first simulation study is due to the memristor voltage equation given in equation (23). Depending on the change in voltage at the controller input, Memristor receives a resistance value between $R_{\mathrm{ON}}$ and $R_{\text {OFF }}$ values. Therefore, a kind of chattering effect occurs in the control signal. In this simulation study, chattering effect was eliminated by adjusting the $R_{\mathrm{ON}}$ and $R_{\mathrm{OFF}}$ values. In the future, it is planned to test the performance of the Controller and the effectiveness of this simulation study on a real system.

\section{REFERENCES}

[1] Chua, L. O. (1971). Memristor - the missing circuit element. IEEE Trans. Circuit Theory, 18(5), 507-519. https://doi.org/10.1109/TCT.1971.1083337

[2] Strukov, D. B., Snider, G. S., Stewart, D. R., \& Williams, R. S. (2008). The missing memristor found. Nature, 453(7191), 80. https://doi.org/10.1038/nature06932

[3] Pershin, Y. V. \& Di Ventra, M. (2010). Practical approach to programmable analog circuits with memristors. IEEE Transactions on Circuits and Systems I: Regular Papers, 57(8), 1857-1864. https://doi.org/10.1109/TCSI.2009.2038539

[4] Tetzlaff, R. (2013). Memristors and memristive systems. Springer Science \& Business Media. https://doi.org/10.1007/978-1-4614-9068-5

[5] Yang, J. J., Strukov, D. B., \& Stewart, D. R. (2013). Memristive devices for computing. Nature nanotechnology, 8(1), 13. https://doi.org/10.1038/nnano.2012.240
[6] Zhu, S., Wang, L., \& Duan, S. (2015). Memristor-based neural network PID controller for buck converter. 2015 Sixth International Conference on Intelligent Control and Information Processing (ICICIP), 36-41. https://doi.org/10.1109/ICICIP.2015.7388140

[7] Alharbi, A. G., Fouda, M. E., \& Chowdhury, M. H. (2015). Memristor emulator based on practical current controlled model. 2015 IEEE 58th International Midwest Symposium on Circuits and Systems (MWSCAS), 1-4. https://doi.org/10.1109/MWSCAS.2015.7282109

[8] Sánchez-López, C., Morales-López, F. E., \& CarrascoAguilar, M. A. (2016). High-level simulation of a PID controller based on memristor. 2016 14th IEEE International New Circuits and Systems Conference (NEWCAS), 1-4. https://doi.org/10.1109/NEWCAS.2016.7604830

[9] Vaidyanathan, S. \& Volos, C. (2017). Advances in memristors, memristive devices and systems. Springer. https://doi.org/10.1007/978-3-319-51724-7

[10] Zhang, S. \& Wang, Y. (2016). The simulation of BLDC motor speed control based-optimized fuzzy PID algorithm. 2016 IEEE International Conference on Mechatronics and Automation, 287-292. https://doi.org/10.1109/ICMA.2016.7558576

[11] Utomo, D. S. B., Rizal, A., \& Gaffar, A. F. O. (2017). Model reference neural adaptive control based BLDC motor speed control. 2017 5th International Conference on Electrical, Electronics and Information Engineering (ICEEIE), 49-54. https://doi.org/10.1109/ICEEIE.2017.8328761

[12] Hassan, A. K., Saraya, M. S., Elksasy, M. S., \& Areed, F. F. (2018). Brushless DC motor speed control using PID controller, fuzzy controller, and neuro fuzzy controller. International Journal of Computer Applications, 180(30), 47-52. https://doi.org/10.5120/ijca2018916783

[13] Verma, V., Pal, N. S., \& Kumar, B. (2019). Speed Control of the Sensorless BLDC Motor Drive Through Different Controllers. Harmony Search and Nature Inspired Optimization Algorithms, 143-152. Springer, Singapore. https://doi.org/10.1007/978-981-13-0761-4_15

[14] Ebrahimkhani, S. (2016). Robust fractional order sliding mode control of doubly-fed induction generator (DFIG)based wind turbines. ISA transactions, 63, 343-354. https://doi.org/10.1016/j.isatra.2016.03.003

[15] Du, H., Yu, X., Chen, M. Z., \& Li, S. (2016). Chattering-free discrete-time sliding mode control. Automatica, 68, 87-91. https://doi.org/10.1016/j.automatica.2016.01.047

[16] Xiong, J. J. \& Zhang, G. B. (2017). Global fast dynamic terminal sliding mode control for a quadrotor UAV. ISA transactions, 66, 233-240. https://doi.org/10.1016/j.isatra.2016.09.019

[17] Li, H., Wang, J., Du, H., \& Karimi, H. R. (2017). Adaptive sliding mode control for Takagi-Sugeno fuzzy systems and its applications. IEEE Transactions on Fuzzy Systems, 26(2), 531-542. https://doi.org/10.1109/TFUZZ.2017.2686357

[18] Du, H., Chen, X., Wen, G., Yu, X., \& Lü, J. (2018). Discretetime fast terminal sliding mode control for permanent magnet linear motor. IEEE Transactions on Industrial Electronics, 65(12), 9916-9927. https://doi.org/10.1109/TIE.2018.2815942

[19] Murali, S. B. \& Rao, P. M. (2018). Adaptive sliding mode control of BLDC motor using cuckoo search algorithm. 2018 2nd International Conference on Inventive Systems and Control (ICISC), 989-993. https://doi.org/10.1109/ICISC.2018.8398950

[20] Peter, I., Chang, T., Lin, X. Y., \& Yu, I. J. (2019). Sensorless BLDC Motor Sliding Mode Controller Design for Interference Recovery. 2019 6th International Conference on Control, Decision and Information Technologies (CoDIT), 1780-1785.

https://doi.org/10.1109/CoDIT.2019.8820383 
[21] Mousmi, A., Abbou, A., El Houm, Y., \& Bakouri, A. (2019). Real time implementation of a super twisting control of a BLDC motor. International Journal of Electrical and Computer Engineering (IJECE), 9(4), 3032-3040. https://doi.org/10.11591/ijece.v9i4.pp3032-3040

[22] Divandari, M., Rezaie, B., \& Noei, A. R. (2019). Speed control of switched reluctance motor via fuzzy fast terminal sliding-mode control. Computers \& Electrical Engineering, 80, 106472. https://doi.org/10.1016/j.compeleceng.2019.106472

[23] Orman, K. Real-Time Speed Control of BLDC Motor Using Adaptive Fuzzy Fractional Sliding Mode Controller. International Journal of Applied Mathematics, Electronics and Computers, 6(4), 45-52.

https://doi.org/10.18100/ijamec.2018447370

[24] See https://www.maxonmotor.com/medias/sys master/ root/8825424085022/17-EN-218.pdf

[25] Babacan, Y., Yesil, A., \& Kacar, F. (2017). Memristor emulator with tunable characteristic and its experimental results. AEU-International Journal of Electronics and Communications, 81, 99-104. https://doi.org/10.1016/j.aeue.2017.07.012

[26] Mazumder, P., Kang, S. M., \& Waser, R. (2012). Memristors: devices, models, and applications. Proceedings of the IEEE, 100(6), 1911-1919. https://doi.org/10.1109/JPROC.2012.2190812

[27] Jezernik, K., Rodič, M., \& Curk, B. (1997). Neural network sliding mode robot control. Robotica, 15(1), 23-30. https://doi.org/10.1017/S0263574797000040

[28] Derdiyok, A. \& Levent, M. (2000). Sliding mode control of a bioreactor. Korean Journal of Chemical Engineering, 17(6), 619-624. https://doi.org/10.1007/BF02699106

[29] Wang, X., Zhao, Y., \& Liao, Y. (2011, March). Dynamic performance analysis of PID controller with one memristor. In International Conference on Information Science and Technology, 1234-1237.

[30] Yener, S. C., Mutlu, R., \& Kuntman, H. H. (2015). A new memristor-based low-pass filter topology and its smallsignal solution using MacLaurin series. SAT, 1(1), 2. Retrieved from http:// https://oam-rc.inoe.ro/articles/a-newmemristor-based-low-pass-filter-topology-and-its-smallsignal-solution-using-maclaurin-series/fulltext

\section{Contact information}

Kamil ORMAN, Assist. Prof. Dr.

Erzincan Binali Yıldırım Üniversitesi, Mühendislik,

24100 Erzincan, Turkey

E-mail: korman@erzincan.edu.tr 